\title{
Motor and postural control in patients with chronic non-specific low back pain: a blinded, prospective, and controlled cross-sectional study
}

Kay Niemier ( $\sim$ kayniemier@arcor.de)

Westmecklenburg Klinikum

Wolfram Seidel

Klinik für Manuelle Medizin, Sanakliniken Sommerfeld

Engel Kerstin

Sana Kliniken Sommerfeld

Jan Emmereich

Sana Kliniken Sommerfeld

Thomas Wetterling

DRK Schmerzzentrum Mainz

Hans-Raimund Casser

DRK Schmerzzentrum Mainz

Ulf Marnitz

Rückenzentrum am Markgrafenpark

Smolenski Ulrich

Institut für Physiotherapie, Universität Jena

Michaelis Johannes

Klinik für Manuelle Therapie Hamm

Dana Loudovici-Krug

Institut für Physiotherapie, Universität Jena

Research article

Keywords: low back pain, movement control, posture control, clinical tests

Posted Date: December 3rd, 2019

DOI: https://doi.org/10.21203/rs.2.18125/v1

License: (1) (1) This work is licensed under a Creative Commons Attribution 4.0 International License.

Read Full License 


\section{Abstract}

Background Motor and postural control dysfunctions are hypothesized to be important for the development and clinical course of chronic, non-specific low back pain (cLBP).

Objective To compare the motor and postural control deficiencies (MPCD) between patients with cLBP and healthy controls.Methods Blinded, cross-sectional control study using clinical tests examining motor and postural control between patients and healthy controls.

Results We compared the motor and postural control of 46 cLBP patients and 36 healthy controls. Patients with cLBP had significantly more positive pathological tests for movement control (one-leg stance, hip extension, and breathing pattern). No significant differences were observed between groups for tests examining postural control. Patients with CLBP had significantly more trigger points in muscles relevant to postural control.

Conclusions Although we found that, in general, CLBP patients have poorer motor and postural control relative to healthy subjects, not all patients showed poor motor and postural control. Therefore, MPCD might only be relevant for a subgroup of patients with CLBP. Targeted diagnostic and treatment settings as well as preventive interventions for this subgroup should be the aim of further studies.

\section{Background}

Motor and postural control deficiencies (MPCD) contribute to chronic, non-specific low back pain (cLBP) $[1,2]$. However, studies examining training programs to specifically improve MPCD have not shown superiority to general exercise [3], and clinical outcomes are not predictable based on findings of the deep stabilization system [4, 5]. In a previous study, we evaluated clinical tests for movement and postural control in patients with chronic musculoskeletal pain, which indicated that patients with more advanced chronic pain have poorer movement and postural control compared to patients with less advanced disease and that the quantity of MPCD predicts treatment outcome [6].

Because MPCD is not the only factor that influences the course of $\operatorname{cLBP}[7,8]$, subgrouping patients by other criteria that influence cLBP, such as musculoskeletal dysfunction, psychosocial and pathomorphological factors as well as neurophysiological changes of pain reception might be beneficial for improving outcomes. Studies examining specific subgroups of patients with cLBP show promise. A two-week inpatient treatment program directed at MPCD shows long-term improvements in pain intensity, general function, and quality of life $[9,10]$. Lethola et al. showed that specialized treatment of MPCD is superior for reduction of pain intensity to general exercise [11]. Functional restoration programs, which address patients' dysfunctional beliefs and behavior, improve functional performance, pain, and quality of life [12].

MPCD might account for one or more subgroups of patients with $\operatorname{CLBP}[6,13,14,15]$. Insufficient lumbar stabilization $[16,17,18]$, poor coordination $[6,19,20]$, reduced muscular endurance [24], altered 
perception [21, 22, 23, 24], breathing and pelvic floor dysfunction [36], and postural muscle trigger points (TRPs) are relevant to the course of cLBP. Furthermore, these factors seem to influence the course of cLBP independently from other factors such as fear of movement or psychopathologies [6,25].

How MPCD influences CLBP has not been yet established. Motor control dysfunctions might result in an overload of structures/tissues and are responsible for nociception and energy exhaustion [28, 29]. Both are considered causes of muscular tension, with TRPs and segmental dysfunction resulting in nociception and aberrant motor and postural control $[13,14,27,28,29]$.

In this study, we used simple, reliable [30] clinical tests to compare motor and postural control in patients with cLBP and healthy controls. Various aspects of motor and postural control were clinically examined (Tab. 1-3).

\section{Methods}

This study was a prospective, rater-blinded, cross-sectional controlled multicenter study, held at four study centers (hospital departments for the treatment of chronic diseases of the locomotor system, especially chronic pain syndromes). It was approved by the ethics committee of Jena University and conducted according to the declaration of Helsinki. Test selection, documentation, blinding procedures, and training were conducted before the study began.

The study centers recruited patients and healthy controls. After a patient consented to the study, the admitting hospital doctor referred patients to the study. Inclusion criteria included CLBP (defined as Stage 2 and 3 by the Mainz Pain Staging System (MPSS; 31)) and age between 18 and 65 years. The MPSS divides patients into different stages of chronic pain, with stage 1 being the least chronic and stage 3 the highest stage of chronic pain. Exclusion criteria included specific LBP, severe comorbidities (e.g. severe heart failure (NYHA 3 and 4), severe COPD), psychiatric diseases, neurological diseases, known pregnancy, non-consent, cognitive impairment, and inability to speak or read German. Healthy controls were recruited regionally by announcement via advertisement in the hospital public areas and reported to the study secretary of the departments. Volunteers were considered healthy by the absence of: current LBP, any LBP within the last 12 months, more than one episode of LBP in the past resulting in medical treatment (medication, physiotherapy, injections), and any spinal operation or joint replacement.

All patients and healthy controls were asked to fill out a quality of life questionnaire (SF12; physical and psychological subscales). The study nurse-secretary scheduled examinations for both groups with the study doctor or physiotherapist, who were blind to patient grouping. The examining doctor or physiotherapist was trained prior to the study and followed a fixed examination schedule. The tests, direct and indirect assessments of motor and postural control, were documented as either positive or negative (Tab. 1). These tests come from various schools of manual medicine or physiotherapy and have been found to have moderate to good inter/intra-rater reliability (kappa 0.6-0.8; 30). They examine spontaneous movements, directed movements, postural pattern, movements or postures considered to provoke special postural reactions, and secondary signs of muscle strain in postural muscles (TRPs). 
The postural patterns examined were adapted from the crossed syndromes according to Janda, who divided muscles into predominantly tonic and phasic/stabilizing muscles, which have a tendency towards tension/shortening and weakening, respectively [32]. Both result in the typical postures and muscle patterns indicative of poor postural control (Tab. 2). Furthermore, the diaphragm and pelvic floor are muscles critical to stabilization of the spine. TRPs are signs of strain in these postural muscles and, therefore, a sign of poor motor and postural control (Tab. 3).

In order to see if some tests are more specific for CLBP, examinations testing for MPDC not considered relevant for CLBP were included into the study (Tab. 1-3).

We used SPSS (IBM SPSS Statistics, Version 22) for statistical analyses. To detect differences between motor control patterns in cLBP patients and healthy controls, we used the chi-square test. To compare both groups reported psychometric parameters and quality of life, we used the Mann-Whitney-U Test for independent samples. Differences were considered statistically significant if $p \leq 0.05$.

\section{Results}

We recruited 53 cLBP patients and 45 healthy controls to the study. Due to missing data, the sample size was reduced to 46 patients and 37 controls, in which the mean age was 47.7 years [24-59] and the composition $63.4 \%$ female (53 females, 30 males). No statistically significant differences existed between the groups regarding sex or age. Due to missing data, the quality of life questionnaire (SF12) was further reduced to $33 \mathrm{cLBP}$ patients and 22 healthy controls.

We observed significantly lower quality of life scores in CLBP patients for both physical and mental health (Tab. 4). Among cLBP patients, the average pain intensity on a scale of 0-100 was "medium" at 56. Five patients had pain during 6 months, three between 6 and 12 months, nine between 12 and 24 months, 10 between 24 months and 5 years, and the remaining 56 had experienced pain for longer than 5 years.

Clinical tests not thought to be relevant for cLBP showed no statistically significant differences in the frequency of positive findings between healthy controls and patients (Fig. 1), but tests considered relevant to cLBP showed disparate results. Dysfunctional breathing patterns were significantly more common in CLBP patient for breathing pattern 1 but not for breathing patterns 2 and 3 (Fig. 2). Tests for stabilization and coordination of the pelvis indicated that an altered one-leg stance or hip extension is present significantly more often in CLBP patients than in healthy controls (two and three times more frequent, respectively; Fig. 3).

Poor postural control, as indicated by Janda's crossed syndromes, tended to be more frequent in patients than in healthy controls. Although almost $20 \%$ more cLBP patients had lower crossed syndrome I and almost twice as many had a lower crossed syndrome II, these findings were not statistically significant (Fig. $4 ; p=0.072$ and 0.137 , respectively). Lumbar stability and indirect assessments of stability and coordination were not significantly different between groups (Fig. 5, 7). 
Pelvic floor TRPs were significantly more common in CLBP patients, occurring four times more often than in healthy controls. Diaphragmatic TRPs were nearly twice as common in cLBP patients, but this difference was not statistically significant ( $p=0.087$; Fig. 6).

\section{Discussion}

This study was performed to clinically examine whether patients with cLBP have altered movement and/or postural control relative to healthy controls. We found no differences in patient age or gender between groups, so the detected variance in the motor control and postural control is neither age-nor gender-related. Duration of pain and impact on quality of life indicate that the patients with CLBP in this study are comparable to other, previously studied groups of patients $[6,33]$.

Consistent with previous findings, MPCD was more common in the CLBP group $(1,2)$. To determine whether CLBP is related to MPCD generally or to specific features of MPCD, we included tests relevant to MPCD but not CLBP. Positive results for these tests, which assessed postural and movement control of the shoulder and neck region, did not differ in frequency between the two groups, suggesting that disturbances of motor and postural control are specific to the affected region. To our knowledge, there are no studies comparing patients with different pain syndromes and, therefore, different MPCD. It would be interesting to evaluate further whether MPCD are complaint-specific or a general problem related to chronic pain (34).

The Vele and Matthias Tests did not demonstrate significant differences in coordination and the deep stabilization system between the two groups, and, surprisingly, more healthy controls than cLBP patients showed the dysfunctional pattern. We recommend rejecting or revising these assessments of postural reactions.

Dysfunction in tests that assess stabilization of the lumbar spine (hip flexion 1 and 2, sit ups) was not significantly different between groups, with high frequency in both patients and controls. We therefore question whether the movement patterns thought to be dysfunctional (Tab. 1) are normal variants. However, others have suggested that movement and postural control in patients are only altered under high strain to the locomotor system $(1,2)$. Therefore, combining tasks e.g. checking for pelvic and lumbar stability, might help to differentiate between patients and healthy subjects.

As tests of movement and postural control of the pelvis, one-leg stance and hip extension were significantly more common in patients than controls, but hip abduction was not. This finding supports the idea that MPCD of the pelvic/lumbosacral region might contribute to the development of cLBP. Indeed, high activation of the $\mathrm{M}$. erector spinae and decreased motor response variability of the pelvic region are correlated to $\operatorname{cLBP}[35,36,37]$. However, it is not clear if poor movement control is primary or whether it is secondary to the pain $[34,38]$. On the other hand, MPCD is known to persist after an acute episode of musculoskeletal pain [40]. It seems plausible that persistent MPCD is a risk factor for recurrence and chronicity of LBP $[6,40]$, which these simple clinical tests might help to prevent. 
The pelvic floor and diaphragm are important postural muscles. TRPs in these muscles are indirect signs of poor postural control $[6,1541]$. In this study, we found pelvic floor TRPs significantly more often in CLBP patients than in healthy controls. Although the difference in frequency of TRPs in the diaphragm was not statistically significant, it was almost twice as high in CLBP patients than controls but did not reach statistical significance, likely due to the relatively small number of participants and infrequency of this dysfunction. In addition, we found that groups differed in breathing pattern 1 (Fig. 2). Thus, our results support the growing evidence that the pelvic floor and diaphragm are important for spinal stabilization and that impaired function might be a relevant factor in the development of $\operatorname{cLBP}[41,42]$. The tests we used to assess these features are easy and quick to perform; their incorporation into physiotherapy practices and chronic pain management might help to detect patients in this subgroup.

Finally, the crossed syndromes tests for postural control indicated that more cLBP patients were affected by these dysfunctions, but the differences did not reach statistical significance. Again, this is probably caused by the relatively small number of participants in this study. In addition, the presence of MPCD has previously been described as detectable only under additional stress to the locomotor system (1). Our tests might require refinement to differentiate between postural control in patients and healthy controls.

Although our results elucidate motor and postural control dysfunction in a population of patients with cLBP, our study was limited by the overall small number of participants, which restricts the sensitivity of our analyses. Furthermore, we recruited and examined more patients than healthy controls, which limited our ability to detect differences between these populations. Finally, because we lacked funding for a dedicated study nurse, our analyses suffered from missing data, especially for the quality of life questionnaire.

\section{Conclusions}

Using simple, clinical tests, we showed differences in movement control between cLBP patients and healthy controls. Some of the functional tests showed a statistically significant difference between patients and healthy controls. However, many patients with CLBP demonstrated negative test results. Therefore, MPCD might only play a role in a subgroup of patients with CLBP. Because a broad variety of MPCD has been observed in patients with $\operatorname{cLBP}[43,44]$, the manner in which MPCD manifests may vary across CLBP patients. Thus, subgrouping might be necessary to define the correct functional treatment strategy for each individual patient [46]. Further research into clinical subgrouping of patients with cLBP including functional, psychosocial, pathomorphological, and neurophysiological aspects of pain chronicity will help to elucidate the etiology of CLBP and to identify effective strategies to treat and prevent it.

\section{Abbreviations}

CLBP 
Chronic non-specific low back pain

COPD

Fig.

Chronic obstructive pulmonary disease

Figure

LBP

Low back pain

M.

Muscle

MPCD

Motor and postural control deficiencies

MPSS

Mainz Pain Staging System

NYHA

New York Heart Association (Staging of heart failure)

SF12

Short form 12 (quality of life questionnaire)

SPSS

Tab.

Statistical Package for the Social Science

Table

TRPs

Muscle trigger points

\section{Declarations}


Ethics approval: The study was approved by the ethics commitee of Jena University Hospital.

Patient/Control Consent: Patients and healthy controls were admitted to the study only after consenting to the study

Consent to publish: Patients and healthy controls consented to the publication of the obtained data

Availability of Data: All data generated or analyzed during this study are included in this published article.

Competing interests: The authors declare that they have no competing interests.

Authors contributions: All authors are listed and have contributed substantially to the manuscript. There are no conflicts of interest resp. disclosures to be meant.

$\mathrm{KN}$ : study design, calculation of the results, supervising study centers, data collection, writing of the manuscript

WS, KE, JE, HRC, TW, UM, JM: data collection, conduct of the study

UCS - support of the study design

DLK: calculation of the Results, reviewing the manuscript

Funding: No further funding has to be declared.

Acknowledgements: not applicable

\section{References}

(1) Koch C. and Hänsel F. Non-specific Low Back Pain and Postural Control During Quiet Standing-A Systematic Review. Front Psychol. 2019;10:586 
(2) Koch C. and Hänsel F. Chronic Non-specific Low Back Pain and Motor Control During Gait. Front Psycho 2018; 9:2236.

(3) Saragiotto BT, Maher CG, Yamato TP, Costa LO, Menezes Costa LC, Ostelo RW, Macedo LG (2016) Motor control exercise for chronic non-specific low-back pain. Cochrane Database Syst Rev. 2016;8(1):CD012004

(4) Oliveira C.B., Pinto R.Z., Schabrun S.M., Franco M.R., Morelhão P.K., Silva F.G., Negrão Filho R.F. Association between clinical tests related to motor control dysfunction and changes in pain and disability after lumbar stabilization exercises in patients with chronic low back pain. Archives of Physical Medicine and Rehabilitation 2019;100:1226

(5) Wong A.L., Parent E.C., Funabashi M., Stanton T.R., Kawchuk G.N. Do various baseline characteristics of transversus abdominis and lumbar multifidus predict clinical outcomes in nonspecific low back pain? A systematic review. Pain 2013;154:2589

(6) Niemier K., Seidel W. Der Einfluss von muskulo-skeletaler Funktionsstörung auf chronische Schmerzsyndrome des Bewegungssystems. Schmerz 2007;21:139

(7) Gatchel R.J., Peng Y.B., Peters M.L., Fuchs P.N., Turk D.C. The biopsychosocial approach to chronic pain. Scientific advances and future directions. Psychol Bull. 2007;133:581

(8) Hasenbrink M. Biopsychosoziale Krankheitsmodelle in Rücken- und Nackenschmerzen. Interdisziplinäre Diagnostik und Therapie, Versorgungspfade, Patientenedukation, Begutachtung, Langzeitbetreuung (Casser H.R., Hasenbrink M., Becker A., Baron R. (eds) Springer 2016:206-215

(9) Steinmetz A., Psczolla M., Seidel W., Niemier K, Derlien S , Nisser J. Effect of subgroup-specific multimodal therapy on chronic spinal back pain and function - a prospective inpatient multicentre clinical trial in Germany. Medicine 2019;98:13825

(10) Derlien S., Danckwerth F., Alfter S., Henning J., Hogrefe H.-C., Holschmidt J.H., Jungbluth A., Lang C., Menke J., Olsen G., Pioch G., Psczolla M., Seidel W., Smolenski U.C., Thümmel J., Niemier K. Outcomes 
einer stationären multimodalen Komplexbehandlung des Bewegungssystems. Ergebnisse der Pilotphase zur ANOA-Studie. Manuelle Medizin 2016;54:53

(11) Lehtola V., Luomajoki H., Leinonen V., Gibbons S., Airaksinen O. Sub-classification based specific movement control exercises are superior to general exercise in sub-acute low back pain when both are combined with manual therapy: A randomized controlled trial. BMC Musculoskeletal Disorders 2016;17:135

(12) Kohles S., Barnes D., Gatchel R.J., Mayer T.G. Improved physical performance outcomes after functional restoration treatment in patients with chronic low-back pain. Spine 1989;15:1321

(13) Beyer L., Niemier K. Funktionsstörungen am Bewegungssystem. Funktionelle Reagibilität als Grundlage eines optimalen Bewegungsresultats. Manuelle Medizin 2018;56:293

(14) Niemier K., Seidel W., Liefring V., Psczolla M., Beyer L., Ritz W. Von der Funktionsstörung zur Funktionskrankheit. Manuelle Medizin - Was ist der therapeutische Ansatzpunkt. Manuelle Medizin 2018;56:253

(15) Engel K., Seidel W., Niemier K., Beyer L. Myofasziale Dysfunktion in der S2k-Leitline Spezifischer Kreuzschmerz. Manuelle Medizin 2018;56:2015

(16) Hodges P., Richardson C. Inefficient muscular stabilization of the lumbar spine associated with low back pain. A motor control evaluation of transversus abdominis. Spine 1996;21:2640

(17) Hodges P.W. Changes in motor planning of feedforward postural responses of the trunk muscles in low back pain. Exp Brain Res. 2001;141:261

(18) Hodges P.W., Richardson C.A. Delayed postural contraction of transversus abdominis in low back pain associated with movement of the lower limb. J Spinal Disord. 1998;11:46 
(19) Lamoth C.J., Daffertshofer A., Meijer O.G., Beek P.J. How do persons with chronic low back pain speed up and slow down? Trunk-pelvis coordination and lumbar erector spinae activity during gait. Gait Posture 2006; 23:230

(20) van Dieën J.H., Cholewicki J., Radebold A. Trunk muscle recruitment patterns in patients with low back pain enhance the stability of the lumbar spine. Spine 2003;28:834

(21) Leinonen V., Määttä S., Taimela S., Herno A., Kankaanpää M., Partanen J., Kansanen M., Hänninen O., Airaksinen 0. Impaired lumbar movement perception in association with postural stability and motorand somatosensory-evoked potentials in lumbar spinal stenosis. Spine 2002; 27:975

(22) Luomajoki H., Moseley G.L. Tactile acuity and lumbopelvic motor control in patients with back pain and healthy controls. Br J Sports Med. 2011;45:437

(23) Flor H., Braun C., Elbert T., Birnbaumer N. Extensive reorganization of primary somatosen- sory cortex in chronic back pain patients. Neurosci Lett. 1997;224:5

(24) Moseley G.L. I can't find it! Distorted body image and tactile dysfunction in patients with chronic back pain. Pain 2008;140:239

(25) Sung W., Abraham M., Plastaras C., Silfies S.P. Trunk motor control deficits in acute and subacute low back pain are not associated with pain or fear of movement. Spine J. 2015;15:1772

(26) Mense S. Neurobiologische Grundlagen von Muskelschmerz. Schmerz 1999;13:3

(27) Cooper B.Y. Contribution of edema to the sensitization of high-threshold mechanoreceptors of the goat palatal mucosa. J Neurophysiol. 1993;70:512

(28) Sicuteri F., Franchi G., Fanciullacci M. Bradichinina e dolore da ischemia. Settim Med. 1964;52:127 
(29) Niemier K., Schmidt S., Engel K., Steinmetz A., Herms K., Liefring V., Maulhardt A., Wetterling T., Kosup S., Casser R., Jäger G., Törkott S., Bieneck K., Rotter G., Marnitz U., Klein A., Jahr S., Reishauer A., Seidel W. Reliabilität klinischer Tests zur funktionellen Schmerzdiagnostik. Ergebnisse einer Multicenterstudie zur Reproduzierbarkeit von funktionellen Befunden des Bewegungssystems. Der Orthopäde 2009;38:847

(30) Frettlöh J., Maier C., Gockel H.,Hüppe M. Validität des Mainzer Stadienmodells der Schmerzchronifizierung bei unterschiedlichen Schmerzdiagnosen. Schmerz 2003;17:240

(31) Janda V. Manuelle Muskelfunktionsdiagnostik. (Urban \& Fischer, 2000).囚

(32) Niemier K., Schindler M., Volk T., Baum K., Wolf B., Eberitsch J., Seidel W. Wirksamkeit periduraler Steroidinjektionen im Rahmen eines multimodalen Behandlungskonzeptes in der Therapie von nicht radikulären chronischen Rückenschmerzen. Ein randomisierte, doppelverblindete Vergleichsstudie. Schmerz 2015;29:300

(33) Hodges P.W., Tucker K. Moving differently in pain: a new theory to explain the adaptation to pain. Pain 2011;152:S90

(34) Ghamkhar L., Kahlaee A.H. Trunk muscles activation pattern during walking in subjects with and without chronic low back pain: a systematic review. PMR. 2015;7:519

(35) van Dieën J.H., Selen L.P., Cholewicki J. Trunk muscle activation in low-back pain patients, an analysis of the literature. J. Electromyogr Kinesiol. 2003;13:333

(36) Stergiou N., Decker L.M. Human movement variability, nonlinear dynamics, and pathology: is there a connection? Hum Movement Sci. 2011;30:869 
(38) Seay J.F., van Emmerik R.E., Hamill J. Influence of low back pain status on pelvis-trunk coordination during walking and running. Spine 2011;36:E1070

$$
\text { El-Metwally A., Salminen J.J., Auvinen A., Kautiainen H., Mikkelsson M. }
$$

Prognosis of non-specific musculoskeletal pain in preadolescents: a prospective 4-year follow-up study till adolescence. Pain 2004;110:550

(40) Roussel N., Nijs J., Truijen S., Vervecken L., Mottram S., Stassijns G. Altered breathing patterns during lumbopelvic motor control tests in chronic low back pain: a case-control study, Eur Spine J. 2009;18:1066

(41) Smith M.D., Russell A., Hodges P.W. Disorders of breathing and continence have a stronger association with back pain than obesity and physical activity. Aust J Physiother. 2006;52:11

(42) Ayhan C., Bilgin S., Aksoy S., Yakut Y. Functional contributors to poor movement and balance control in patients with low back pain: A descriptive analysis. Journal of Back and Musculoskeletal Rehabilitation 2016;29:477

(43) Luomajoki H., Kool J, Eling de Bruin E.D., Airaksinen O. Movement control tests of the low back; evaluation of the difference between patients with low back pain and healthy controls. BMC Musculoskeletal Disorders 2008;9:170

(44) Luomajoki H., Kool J., Eling de Bruin E.D., Airaksinen O. Improvement in low back movement control, decreased pain and disability, resulting from specific exercise intervention. Sports Medicine, Arthroscopy, Rehabilitation, Therapy \& Technology 2010;2:11

\section{Tables}

Tab. 1. 


\begin{tabular}{|c|c|c|c|c|c|c|}
\hline Background of the test & Test & \multicolumn{2}{|c|}{$\begin{array}{l}\text { Test } \\
\text { thought } \\
\text { to be } \\
\text { relevant } \\
\text { for cLBP }\end{array}$} & Position & Task & Positive \\
\hline \multirow[t]{3}{*}{$\begin{array}{l}\text { Function of diaphragm as relevant } \\
\text { postural muscle for lumbar } \\
\text { stabilization }\end{array}$} & $\begin{array}{l}\text { Breathing } \\
\text { pattern } 1\end{array}$ & Yes & & Sitting & $\begin{array}{l}\text { "Breathe } \\
\text { normally" }\end{array}$ & $\begin{array}{l}\text { Upward } \\
\text { movement of the } \\
\text { thorax }\end{array}$ \\
\hline & $\begin{array}{l}\text { Breathing } \\
\text { pattern } 2\end{array}$ & Yes & & supine & $\begin{array}{l}\text { "Breathe } \\
\text { normally" }\end{array}$ & $\begin{array}{l}\text { Upward } \\
\text { movement of the } \\
\text { thorax }\end{array}$ \\
\hline & $\begin{array}{l}\text { Breathing } \\
\text { pattern } 3\end{array}$ & Yes & & supine & $\begin{array}{l}\text { "Breathe } \\
\text { into your } \\
\text { stomach" }\end{array}$ & $\begin{array}{l}\text { Not able to breath } \\
\text { into abdomen }\end{array}$ \\
\hline \multirow[t]{2}{*}{$\begin{array}{l}\text { Function of scapula-fixating muscles; } \\
\text { coordination/ stabilization of the } \\
\text { shoulder-neck region }\end{array}$} & $\begin{array}{l}\text { Shoulder } \\
\text { abduction }\end{array}$ & & No & Sitting & $\begin{array}{l}\text { "Lift up } \\
\text { your } \\
\text { elbow to } \\
\text { the side" }\end{array}$ & $\begin{array}{l}\text { Early dynamic } \\
\text { activation of the } \\
\text { upper trapezius } \\
\text { muscle }\end{array}$ \\
\hline & $\begin{array}{l}\text { Shoulder } \\
\text { adduction }\end{array}$ & & No & Sitting & $\begin{array}{l}\text { "Pull } \\
\text { your } \\
\text { shoulder } \\
\text { blades } \\
\text { together" }\end{array}$ & $\begin{array}{l}\text { Activation of the } \\
\text { upper trapezius } \\
\text { muscle }\end{array}$ \\
\hline \multirow[t]{2}{*}{$\begin{array}{l}\text { Function of lumbar stabilization, } \\
\text { indirect (compensating psoas muscle } \\
\text { pull when flexing the hip) }\end{array}$} & $\begin{array}{l}\text { Hip } \\
\text { flexion } 1\end{array}$ & Yes & & Sitting & $\begin{array}{l}\text { "Lift up } \\
\text { your } \\
\text { knee" }\end{array}$ & $\begin{array}{l}\text { Movement of the } \\
\text { umbilicus to the } \\
\text { side }\end{array}$ \\
\hline & $\begin{array}{l}\text { Hip } \\
\text { flexion } 2\end{array}$ & Yes & & Standing & $\begin{array}{l}\text { "Lift up } \\
\text { your } \\
\text { knee" }\end{array}$ & $\begin{array}{l}\text { Movement of the } \\
\text { umbilicus to the } \\
\text { side }\end{array}$ \\
\hline $\begin{array}{l}\text { Function of lumbar stabilization; } \\
\text { strength of M. rectus abdominis and } \\
\text { oblique abdominal muscles; movement } \\
\text { direction dependent stabilization }\end{array}$ & Sit ups & Yes & & $\begin{array}{l}\text { Supine, } \\
\text { hands } \\
\text { behind } \\
\text { head, heels } \\
\text { pushed into } \\
\text { ground } \\
\end{array}$ & $\begin{array}{l}\text { "Lift up } \\
\text { your } \\
\text { upper } \\
\text { body" }\end{array}$ & $\begin{array}{l}\text { Ability to lift } \\
\text { upper shoulder } \\
\text { blade from the } \\
\text { ground without } \\
\text { releasing heel } \\
\text { pressure }\end{array}$ \\
\hline \multirow{3}{*}{$\begin{array}{l}\text { Function of pelvic stabilization; } \\
\text { Coordination of pelvic stabilizing } \\
\text { muscles (especially pelvic floor, hip } \\
\text { abducting muscles, gluteal muscles, } \\
\text { transversus abdominis) }\end{array}$} & $\begin{array}{l}\text { Hip } \\
\text { extension }\end{array}$ & Yes & & Prone & $\begin{array}{l}\text { "Lift the } \\
\text { left/right } \\
\text { leg up } \\
\text { straight" }\end{array}$ & $\begin{array}{l}\text { Tilting of the } \\
\text { pelvis }\end{array}$ \\
\hline & $\begin{array}{l}\text { Hip } \\
\text { abduction }\end{array}$ & Yes & & $\begin{array}{l}\text { Lying on } \\
\text { the } \\
\text { right/left } \\
\text { side }\end{array}$ & $\begin{array}{l}\text { "Lift the } \\
\text { upper leg } \\
\text { up" }\end{array}$ & $\begin{array}{l}\text { Turning of the } \\
\text { foot, dynamic } \\
\text { activation of the } \\
\text { M. quadratus } \\
\text { lumborum }\end{array}$ \\
\hline & $\begin{array}{l}\text { One-leg } \\
\text { stance }\end{array}$ & Yes & & Standing & $\begin{array}{l}\text { "Lift up } \\
\text { the } \\
\text { right/left } \\
\text { leg" }\end{array}$ & $\begin{array}{l}\text { Trendelenburg } \\
\text { sign, Duchenne } \\
\text { sign, dynamic } \\
\text { activation of the } \\
\text { M. quadratus } \\
\text { lumborum } \\
\end{array}$ \\
\hline \multirow[t]{2}{*}{$\begin{array}{l}\text { Indirect testing of coordination/ } \\
\text { stabilization (postural reflexes) }\end{array}$} & $\begin{array}{l}\text { Matthias } \\
\text { Test }\end{array}$ & Yes & & $\begin{array}{l}\text { Standing, } \\
\text { arms } \\
\text { stretched } \\
\text { out to the } \\
\text { front } \\
\end{array}$ & $\begin{array}{l}\text { "Stand } \\
\text { for } 20 \\
\text { seconds" }\end{array}$ & $\begin{array}{l}\text { Back-bending of } \\
\text { the torso }\end{array}$ \\
\hline & Vele Test & Yes & & Standing & $\begin{array}{l}\text { "Shift } \\
\text { your } \\
\text { weight to } \\
\text { the front" }\end{array}$ & Toes not bending \\
\hline
\end{tabular}


Table 2.

\begin{tabular}{|l|l|l|l|l|l|}
\hline Test & Position & $\begin{array}{l}\text { Test thought to } \\
\text { be relevant for } \\
\text { cLBP }\end{array}$ & Positive & Muscle pattern \\
\hline $\begin{array}{l}\text { Upper } \\
\text { srossed } \\
\text { syndrome }\end{array}$ & Standing & & No & $\begin{array}{l}\text { Shoulder and } \\
\text { head } \\
\text { protraction }\end{array}$ & $\begin{array}{l}\text { Weakness: scapula-fixating muscles, deep } \\
\text { neck flexing muscles. } \\
\text { Shortening: upper trapezius muscle, short } \\
\text { neck-extending muscles, M. sterno- } \\
\text { cleidomastoideus }\end{array}$ \\
\hline $\begin{array}{l}\text { Lower } \\
\text { crossed } \\
\text { syndrome I }\end{array}$ & Standing & Yes & & $\begin{array}{l}\text { Lumbar } \\
\text { hyperlordosis }\end{array}$ & $\begin{array}{l}\text { Weakness: transverse abdominal muscle } \\
\text { Shortening: Mm. erector spinae (lumbar spine) }\end{array}$ \\
\hline $\begin{array}{l}\text { Lower } \\
\text { crossed } \\
\text { syndrome II }\end{array}$ & Standing & Yes & & $\begin{array}{l}\text { Forward tilt } \\
\text { pelvis }\end{array}$ & $\begin{array}{l}\text { Weakness: gluteal muscles } \\
\text { Shortening: hip flexing muscles }\end{array}$ \\
\hline
\end{tabular}

Tab. 3.

\begin{tabular}{|l|l|l|l|}
\hline Test & Position & Test thought relevant for cLBP & Positive \\
\hline TRP pelvic floor & Lying right or left side & Yes & Palpable TRP \\
\hline TRP diaphragm & Sitting, bending forward & Yes & Palpable TRP \\
\hline
\end{tabular}

Tab. 4.

\begin{tabular}{|l|l|l|l|l|l|}
\hline Test & Group & $\mathbf{N}$ & Mean & Standard deviation & $\mathbf{p}$ \\
\hline SF12 physical & cLBP patients & 33 & 33.97 & 8.43 & $<0.001$ \\
\cline { 2 - 5 } & controls & 22 & 53.02 & 5.85 & \\
\hline \multirow{2}{*}{ SF12 psychological } & cLBP patients & 33 & 42.24 & 12.81 & \multirow{2}{*}{0.003} \\
\cline { 2 - 5 } & controls & 22 & 52.28 & 6.79 & \\
\hline
\end{tabular}

\section{Figures}




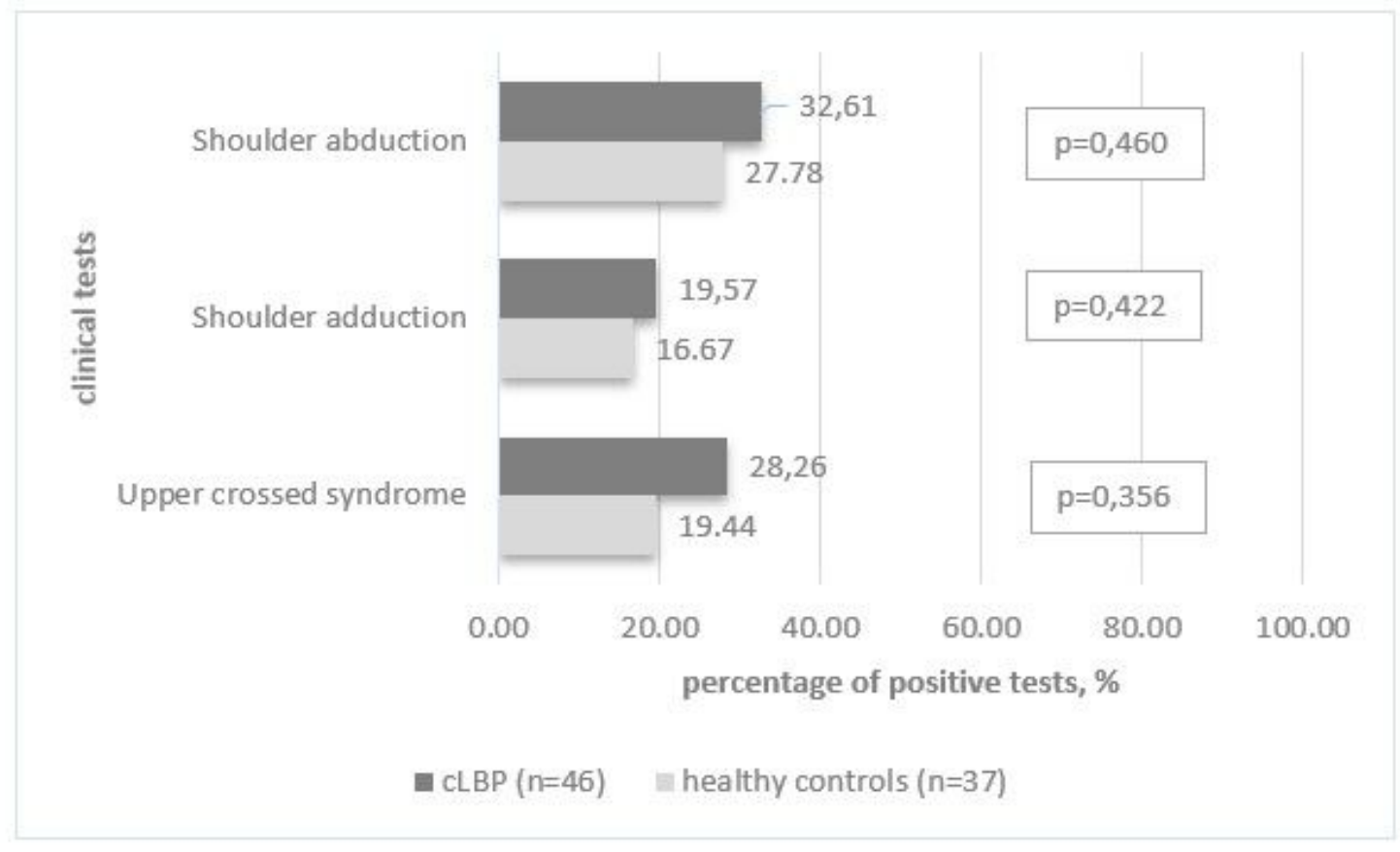

Fig. 1.

\section{Figure 1}

Performance of chronic lower back pain (cLBP) patients and healthy controls in physiotherapy tests unrelated to chronic lower back pain (cLBP). 


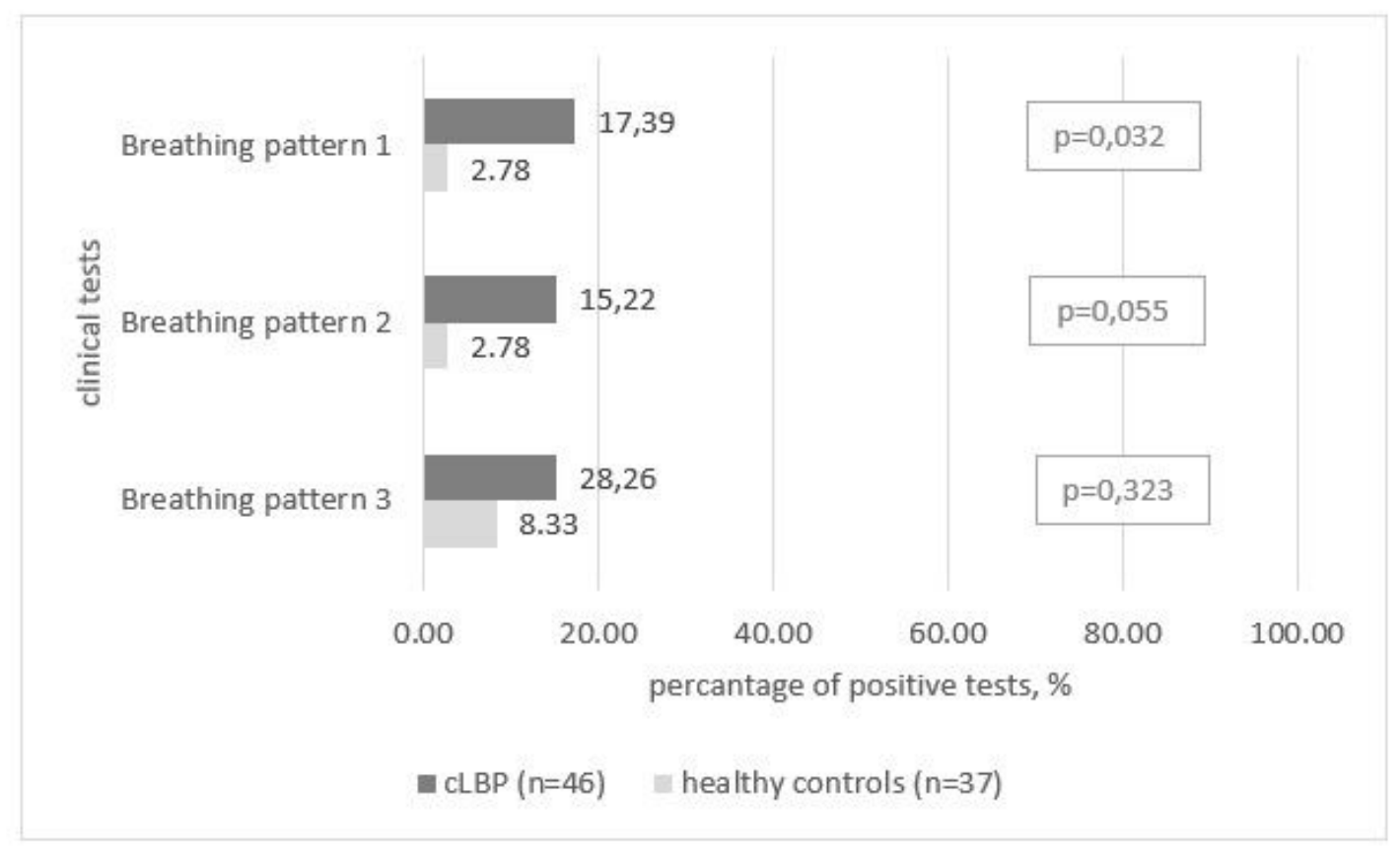

Fig. 2.

Figure 2

Performance of breathing patterns in patients with chronic low back pain (cLBP) and healthy controls. 


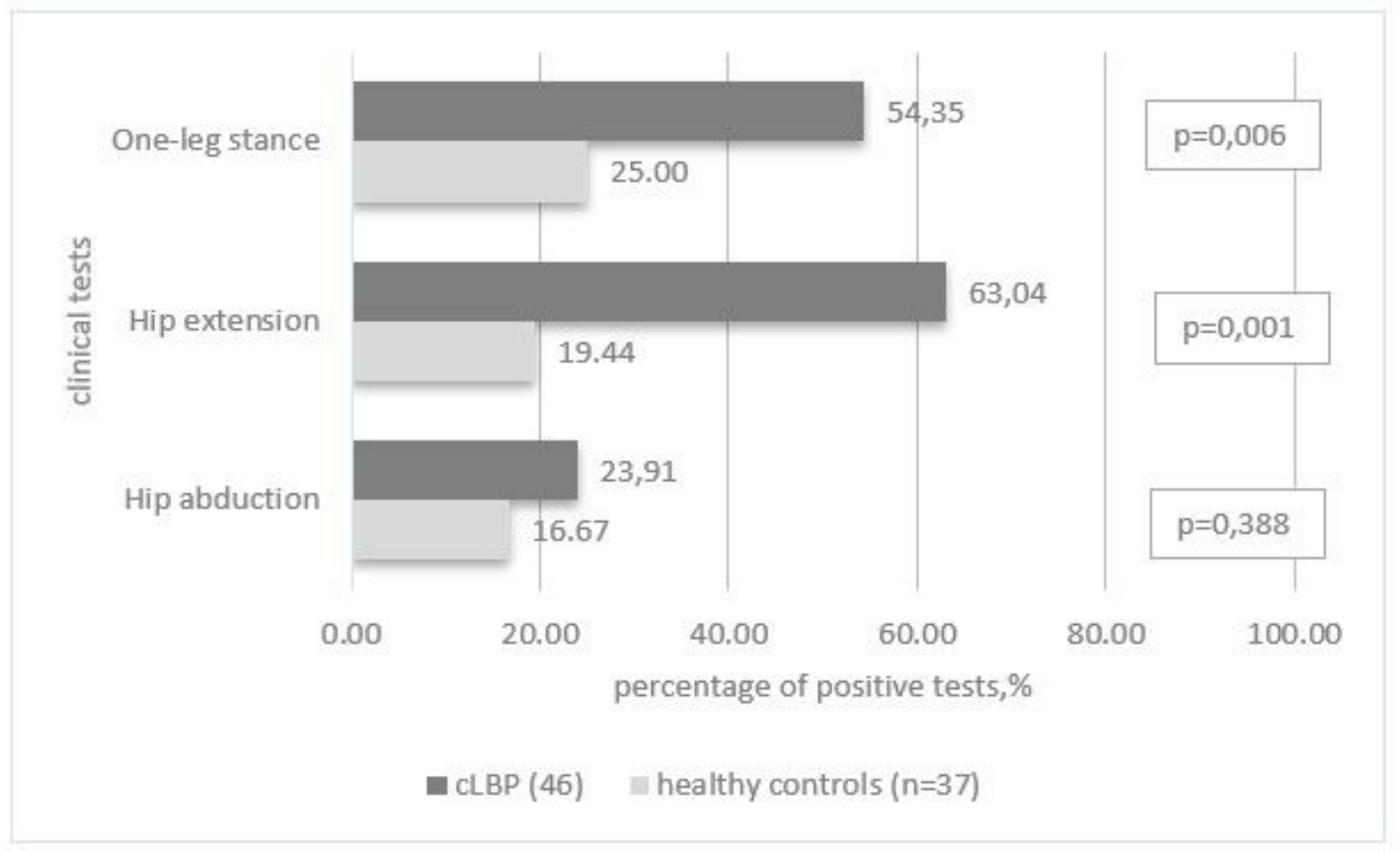

Fig. 3.

\section{Figure 3}

Pelvic stabilization/coordination in chronic lower back pain (cLBP) patients and healthy controls. 


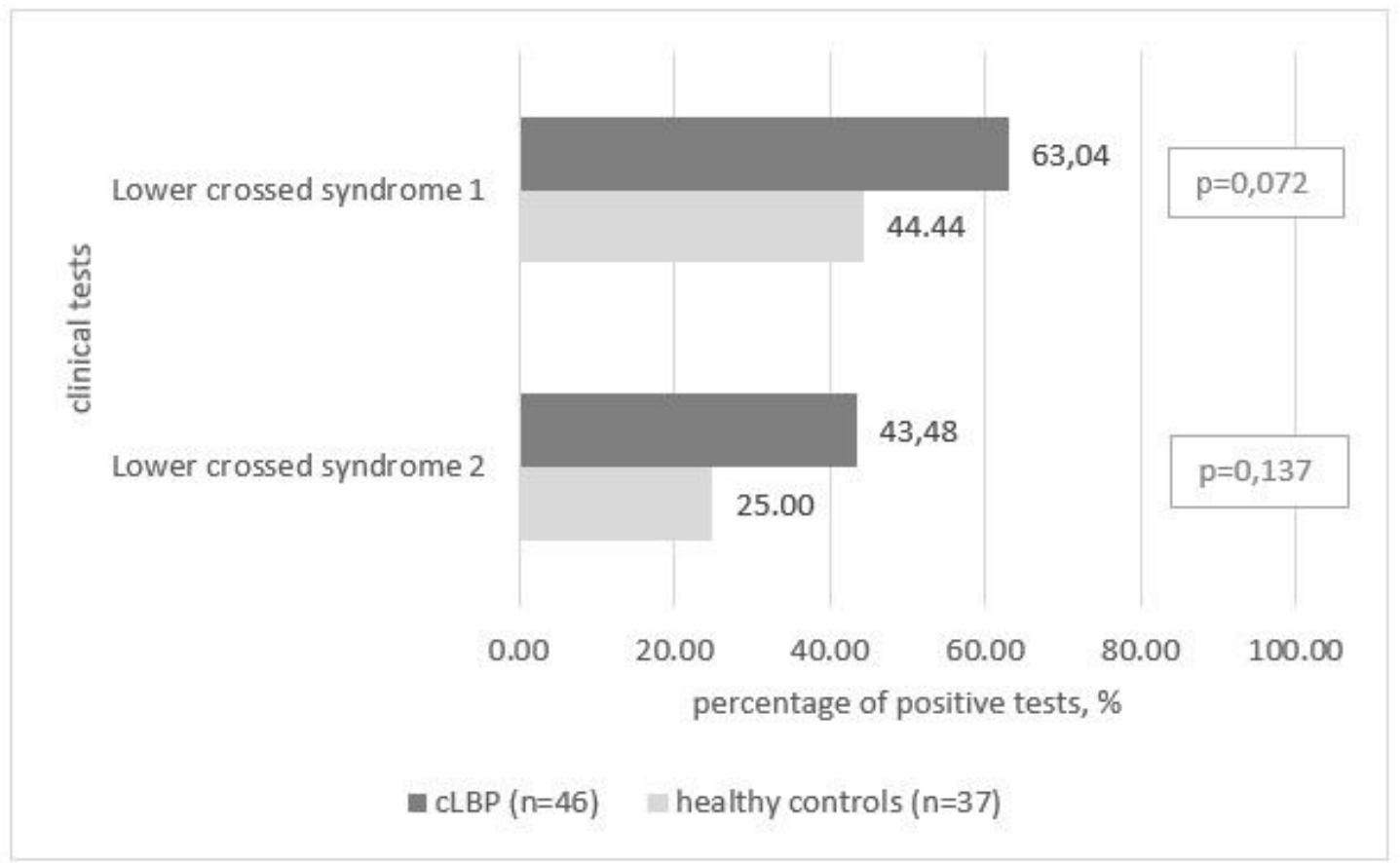

Fig. 4.

\section{Figure 4}

Postural control in chronic lower back pain (cLBP) patients and healthy controls, as assessed by Janda's crossed syndromes. 


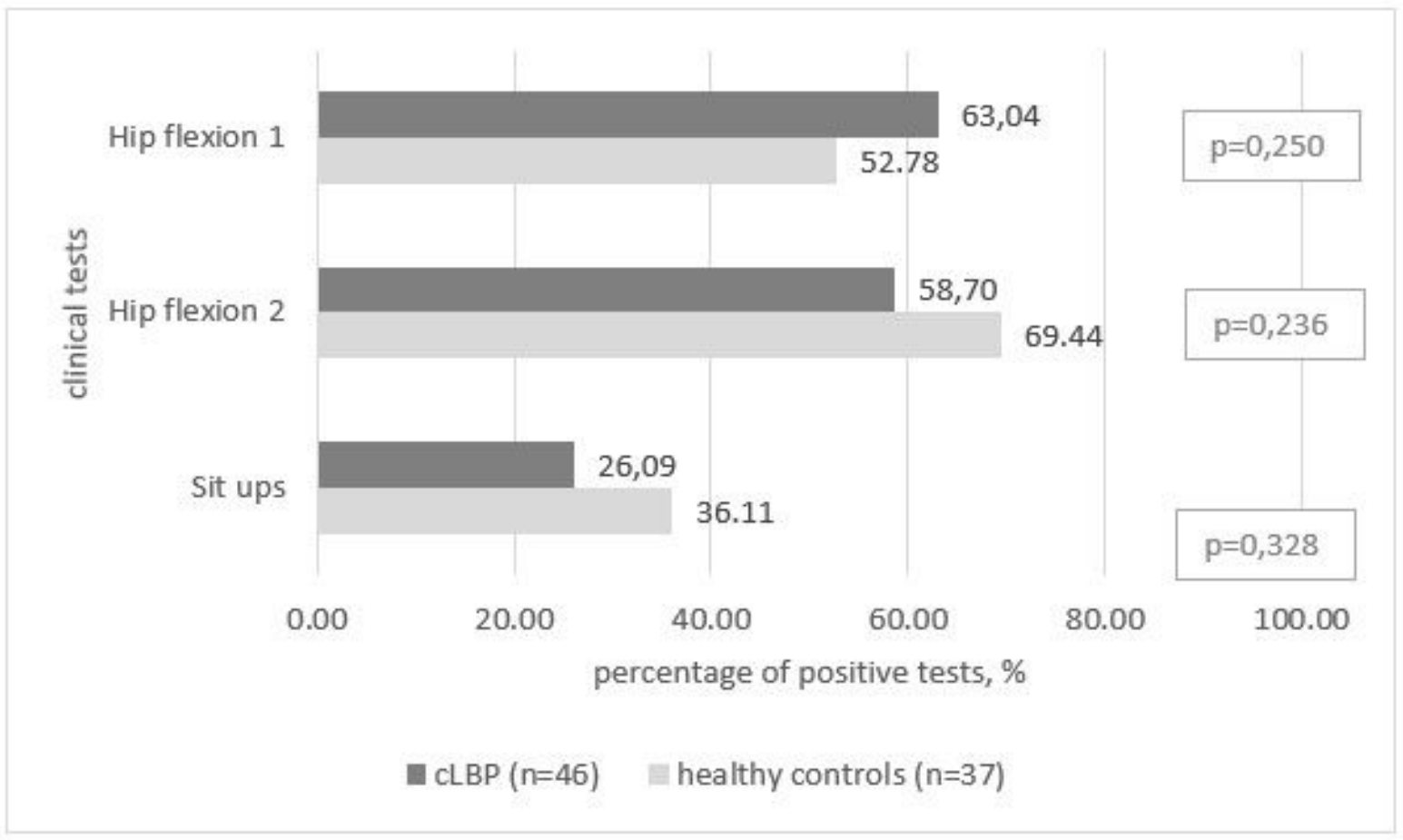

Fig. 5.

\section{Figure 5}

Lumbar stability assessments in chronic lower back pain (cLBP) patients and healthy controls. 


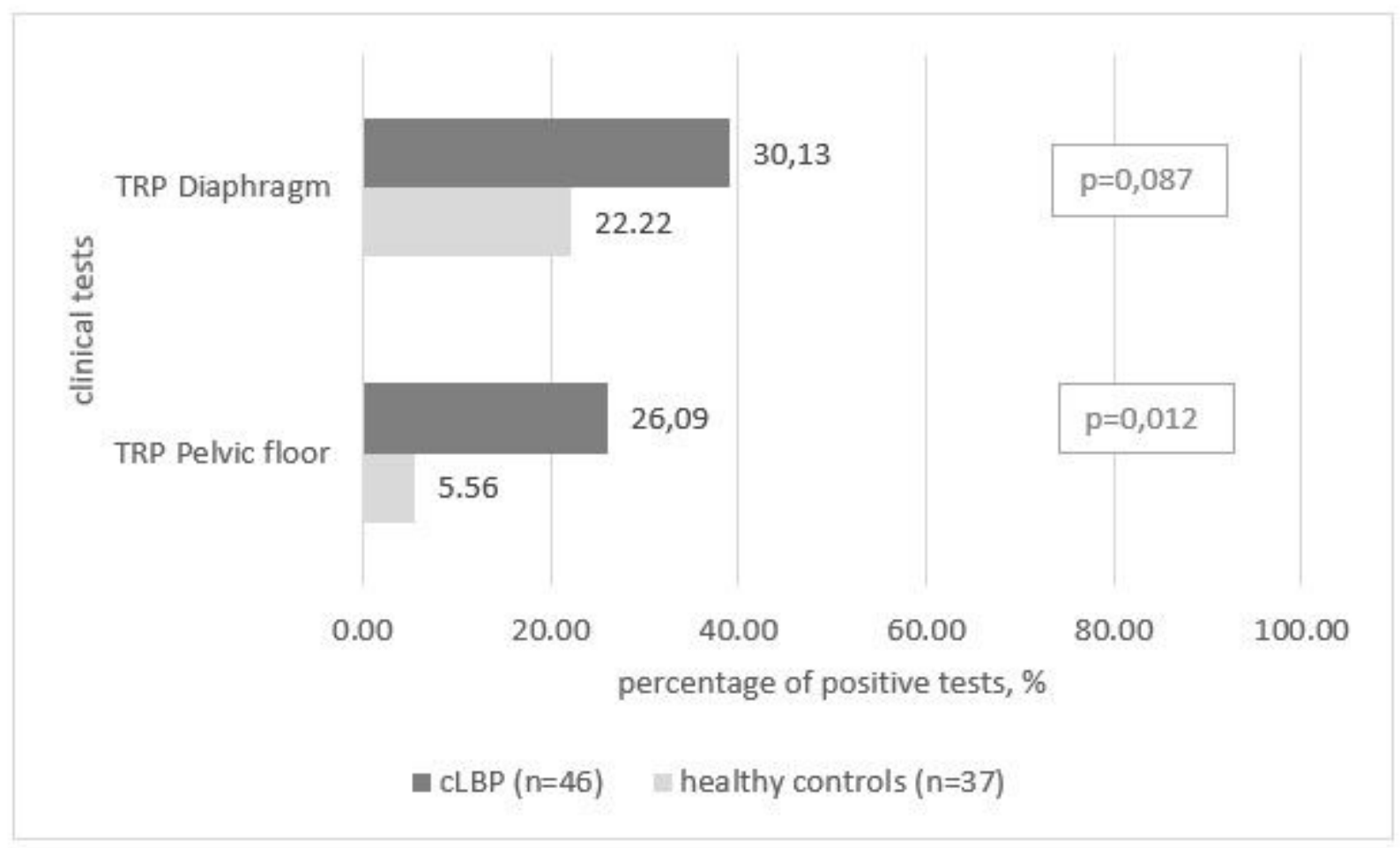

Fig. 6.

Figure 6

Postural muscle trigger points in chronic lower back pain (CLBP) patients and healthy controls. 


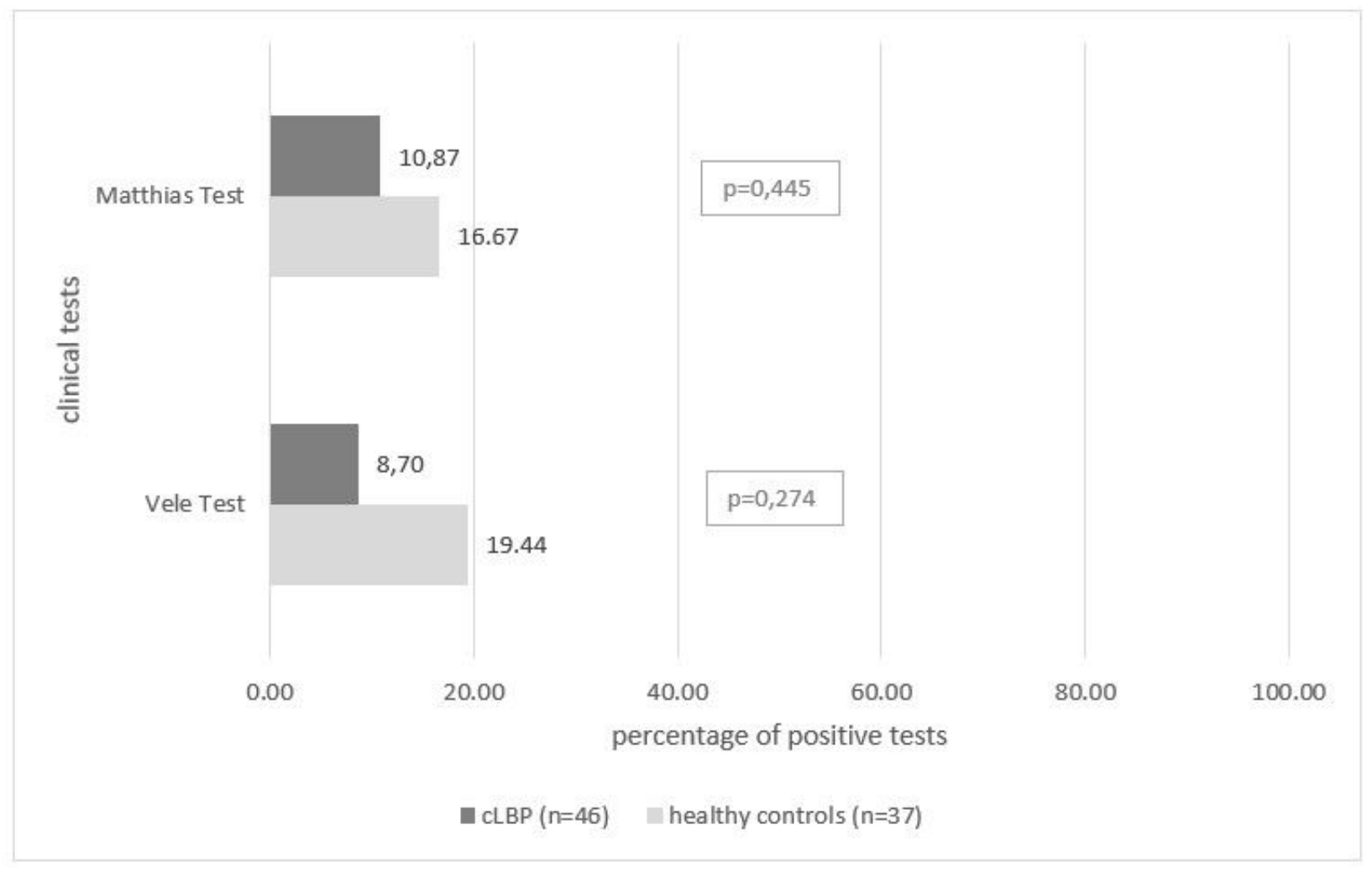

Fig. 7.

\section{Figure 7}

Indirect testing of stability and coordination in chronic lower back pain (cLBP) patients and healthy controls. 